think Kittel has been over-cavalier, because unnecessarily so, is on the question of a priori probability. He justifies his approach by a long quotation from Tolman's celebrated treatise-a passage that I have never regarded as one of the glories of this work, and even further enfeebled here by the omission of a few sentences that are crucial to the meaning. I hope that in later editions, which the book surely deserves, a rather deeper analysis including reference to Liouville's theorem will be inserted. A. B. Pippard

\section{VIBRATIONAL ENERGY}

\section{Transfer and Storage of Energy by Molecules}

Edited by George M. Burnett and Alastair M. North. Vol. 2: Vibrational Energy. Pp. xix +410 . (Wiley (Interscience): London, December 1969.) $140 s$.

KNOWLEDGE about the transfer and storage of vibrational energy by molecules is fundamental to the understanding of all chemical processes. The techniques for its investigation range over fields as varied as acoustics, shock-waves and spectroscopy, so that the large amount of interesting work which has been published is scattered in a wide variety of journals and reviews. The publication of this monograph, which brings all this information together, in articles written by experts who are actually ongaged in the work described, is both timely and welcome.

The first chapter is about measurement of vibrational relaxation times in gases. It gives a very clear account of the basic theory of the acoustic methods of measurement, followed by a description of the kind of apparatus used, and a brief account of the optical methods of investigation, including the most recent pulsed infrared laser techniques. The second chapter begins with a critical comparison of the classical, semi-classical and quantum mechanical theories of vibration-translation and vibration-vibration transfer, leading on to a comprehensive survey of the large body of experimental measurements now available for both diatomic and polyatomic molecules. The third chapter, on measurement of vibrational relaxation rates by shock techniques, gives an account of basic shock-tube practice and theory and discusses recent shock-tube measurements and their significance. This overlaps to a certain extent with the previous chapter, but it is an added advantage to be able to read two different expert points of view on some topics. The fourth chapter, on molecular relaxation processes in liquids, surveys the basic theory of energy relaxation in liquids, which differs in many ways from the phenomena in gases, and describes the essentials of the acoustic methods of investigation. Then follows a fascinating account of how the method can be used to investigate the dynamies of rotational isomerism in organic molecules, and a section on simple vibrational relaxation, which is less easy to observe in liquids than in gases.

The fifth chapter is about collisional excitation and chemical reaction, and the most charitable thing that can be said is that it only occupies twenty pages. It almost passes belief that one can read, in an articlo published thirty-seven years after Michael Polany's classical Atomic Reactions, the statement: "Very little is known about whether vibrational energy of one or both molecules can contribute to the activation process in a bimolecular exchange reaction". Potential enorgy surfaces, which are fundamental to the whole business, are not even mentioned, nor are energy distribution in flames, "hot" molecules or infrared chemiluminescence: only a very superficial survey of conventional chemical kinetics.

With this one, small, cxeeption, this book is a brilliant and authoritative monograph, and a worthy successor to Cottrell and McCoubrey's Molecular Energy Transfer in Gases, published in $196 \mathrm{I}$. It is interesting to see how the subject has both clarified and expanded in nino ycars. The authors of the first four chapters have achieved a balance between technique, basic theory and experimental results, which makes their contributions a pleasure to read.

J. D. Lambert

\section{A MECHANIST'S ENCYCLOPAEDIA}

\section{Structure and Mechanism in Organic Chemistry}

By Sir Christopher K. Ingold. Second edition. Pp. ix $+1,266$. (Bell: London, February 1970.) 250s.

IT is now nearly seventeen years since the first publication of Sir Christopher Ingold's great work, a monument in its time and an all but inexhaustible quarry of factual information; it is therefore with the liveliest interest and expectations that one turns to the second edition. An immediate reaction is to the increase in size (by 438 pages), and the author explains in his preface that though approximately two thirds of the original text have been retained with only minor emendations more than that amount of new writing has been added. Major now topics include homolytic aromatic and aliphatic substitution, homolytic addition, electrophilic aliphatic substitution, the elimination (benzyne) mechanism of nucleophilic aromatic substitution, the addition of phosphate reactions to the existing chapter on carboxyl reactions, the extension of the chapter on olefin-forming eliminations to include acetylenes and carbenes, and interesting now chapters on substitution at hetero-elements, polar energy, and stable radicals. While changes and emendations of existing mattor include such topics as the mechanisms of further electrophilic aromatic substitution reactions including alkylation, nitrosation, desilylation and the like, considerable expansion of the section on the benzidine rearrangement (a singularly useful, definitive summary), and a good deal more on unsaturated rearrangements.

So much for an attempt to indicate some of the changes: the vital question is how well have they worked out in practice. One cannot help but feel that the introductory chapters could, with advantage, have been omitted; they have been published separately from the main work already, they have undergone the least current revision, and a good deal of their content is probably superfluous for serious users of the book: such a course would have had the added advantage of making a prohibitively ex. pensive book quite markedly cheaper. Sir Christopher has throughout retained the detailed historical introdue. tions to topies, and while this can be an excellent thing, particularly in fields such as aliphatic substitution where the author has been so much the prime mover, it can make for difficulty in effecting really satisfactory interweaving with new developments since 1953 to provide, within reasonable compass, an adequately balanced evaluation of the present state of the art. This balance has been achieved particularly well in the section on aromatic electrophilic substitution, where we are presented with a valuable and definitive account; but things have not worked out quite so satisfactorily in some other places, and we are left with relatively little on, for example, arynes, hetarynes and nitrenes, reactive intermediates that have come into considerable prominence since 1953.

A valuable feature of the first edition that has been continued in the second is the provision of a detailed summary of contents, with page numbers, at the beginning of each chapter; though it is only fair to say that it would be very difficult to find one's way about the book without these summaries, as the index leaves a good deal to bo desired -just over eleven pages is pretty skimpy for more than twelve hundred pages of text. The reproduction of structural formulae is poor: several different styles are used indiscriminately and their size and shape differ considerably, making for a number of rather ugly looking pages.

The major value and virtue of the new edition lie in its role as a quarry of factual information; so much is gathored conveniently together here that it will long remain a paradise for "dippers-in". PETER Sykes 